\title{
PSICOLOGÍA
}

\section{Deterioro cognitivo en pacientes crónicos con esquizofrenia internados en el Hospital Psiquiátrico de Asunción. Año 2017}

\author{
María Laura Fois Ibarrola', José Galeano Boselli
}

\begin{abstract}
Resumen
Introducción: En la actualidad se define a la "esquizofrenia como una perturbación del pensamiento sensible al ambiente y harto a menudo persistente o recurrente con un sustrato de disfunción cerebral (cognitiva, perceptiva, anatómica o bioquímica) bastante convincente, que ha sido adquirida (por vía traumática, infecciosa, etc.) y o heredada por medio de los genes" Es un desorden cerebral que deteriora la capacidad de las personas para pensar, para dominar sus emociones, tomar decisiones y relacionarse con los demás. Es una enfermedad psíquica que afecta a la mente, al conjunto de actividades o procesos psíquicos conscientes o inconscientes. El cerebro enferma y entra en crisis debido a la tensión experimentada que actúa como catalizador o detonante de la enfermedad en una persona con predisposición a contraerla. Se tiene conocimiento de que las personas con esquizofrenia acuden por primera vez a un especialista cuando el primer episodio psicótico se ha manifestado. Se estima que los síntomas comenzaron a presentarse de tres a cinco años antes del primer episodio, buscar ayuda a menudo es considerado como un último recurso más que una elección racional. Esta situación pone de manifiesto el hecho de que en general los diagnósticos se realizan tardíamente y por lo tanto hay demora en comenzar el tratamiento efectivo. El Hospital Psiquiátrico de Asunción, tiene 150 pacientes con trastornos, de los cuales 20 pacientes padecen de esquizofrenia tanto graves como leves.
\end{abstract}

Objetivo: Analizar el grado de deterioro cognitivo en pacientes crónicos con esquizofrenia internados en el Hospital Psiquiátrico de Asunción. Año 2017.

Material y Método: Para el presente estudio, se seleccionaron diez pacientes del sexo masculino, con esquizofrenia crónica" para analizar qué grado de deterioro cognitivo afecta la enfermedad y que perspectiva tienen los pacientes de la enfermedad. También aplicó un cuestionario a cuatro profesionales del área de la psicología para comprender la importancia del rol del mismo dentro de un hospital psiquiátrico.

Resultados y Conclusiones: Respecto a la percepción que tienen los pacientes de su enfermedad se observa varios aspectos, en primer lugar que los mismo conocen lo que es la esquizofrenia y lo que conlleva vivir con eso, otro aspecto es que los pacientes sienten que el tratamiento brindado en el hospital les ayuda a mejorar su calidad de

1. Carrera de Psicología, Facultad de Ciencias Humanísticas y de la Educación, Universidad Iberoamericana, Paraguay.

Trabajo de Tesis de Grado.

E-mail: laurifois@gmail.com

DOI: 10.26885/rcei.foro.2017.138 


\section{Depresión y ansiedad como factores de riesgo en ideación suicida. Marengo y Bogado}

vida pero que sus familias no hacen un acompañamiento en cuanto al tratamiento y el apoyo es lo más fundamental en estas clases de enfermedades, donde observamos que el profesional tanto psicólogo, psiquiatra y enfermeros/as hacen el papel de familiares por así decirlo en donde dan un acompañamiento emocional. En relación a la importancia del rol del psicólogo dentro del hospital psiquiátrico llegamos a lo siguiente: El mundo de la salud ha estado hegemonizado por el modelo médico, especialmente en la salud mental; la psiquiatría tradicional resulta ser el hilo conductor de los tratamientos con respecto a la esquizofrenia, y en este esquema la Psicología como propuesta y especialmente los psicólogos(as) parecen estar relegados a un desarrollo marginal. Nosotros postulamos la idea de que el psicólogo sí tiene una contribución que aportar a esta realidad y otros fenómenos de interés social, como dar la información correcta de la enfermedad tanto a los pacientes como los familiares.

Finalmente, podemos decir que la Psicología es una ciencia con una presencia relativamente joven en nuestro país, y realizar esta revisión nos reporta una mirada articuladora de nuestro quehacer, una posibilidad de recopilar nuestra historia en el desarrollo de la historia de la esquizofrenia en nuestro propio país.

Palabras clave: deterioro cognitivo, pacientes crónicos, esquizofrenia

\section{Referencias}

Barrero Solís, C. L., García Arrioja, S., Ojeda Manzano, A. (2005). Índice de Barthel (IB): Un instrumento esencial para la evaluación funcional y la rehabilitación. Plasticidad y Restauración Neurológica, 4(1-2), 81-85.

Barrett, S., Mulholland, C., Cooper, T. (2009). Patrones de deterioro neurocognitivo en el primer episodio del trastorno bipolar y esquizofrenia. British Journal of Psychiatry.

Baztán, J.J., Pérez del Molino, J., Alarcón, T., San Cristóbal, E., Izquierdo, G., Manzarbeitia I. (1993). Indice de Barthel: Instrumento válido para la valoración funcional de pacientes con enfermedad cerebrovascular. Rev Esp Geriatr Gerontol, 28, 32-40.

Keefe, R. (2008). ¿Debe incluirse el deterioro cognitivo en los criterios diagnósticos de la esquizofrenia? WorldPsychiatry.

Lagomarsino, A. (1995). Síntomas positivos y negativos de la esquizofrenia. Acta Psiquiátrica y Psicológica de América Latina, 41.

Möller, H.J. (2008). Evaluación del deterioro cognitivo: una adición importante a los criterios diagnósticos de la esquizofrenia. WorldPsychiatry.

Sanjuán, J. \& Balanza, V. (2002). Deterioro cognitivo en la esquizofrenia. Galicia: Asociación Gallega de Psiquiatría. 